\title{
IMPLEMENTASI GERAKAN LITERASI SEKOLAH
}

\author{
Eric Santosa*, Piter Joko Nugroho, Reddy Siram \\ FKIP, Universitas Palangka Raya \\ *E-mail: esantosa203@gmail.com
}

\begin{abstract}
Abstrak: Penelitian kualitatif dengan rancangan studi kasus ini bertujuan untuk mendeskripsikan tentang Implementasi GLS di SDN 5 Menteng Palangka Raya, dilihat dari aspek: (1) tahapan implementasi GLS, (2) Mekanisme implementasi GLS, dan (3) Faktor pendukung dan kendala dalam implementasi GLS. Sumber data dalam penelitian ini adalah kepala sekolah, tenaga pustakawan, dan 2 orang guru kelas. Teknik pengumpulan data dilakukan dengan cara observasi, wawancara, dan dokumentasi. Analisis data menggunakan pola interaktif data dari Miles dan Huberman (1994). Hasil penelitian menunjukan bahwa: (1) Tahapan GLS yang dilaksanakan baru pada tahap awal (pembiasaan berliterasi) melalui aktivitas membaca dan menulis, (2) Mekanisme implementasi GLS dilaksanakan dengan mendasarkan pada prinsip dasar manajemen yaitu: perencanaan GLS, pengorganisasian GLS, penggerakan GLS, serta pengawasan dan evaluasi GLS, (3) Faktor pendukung implementasi GLS meliputi minat yang tinggi dari siswa untuk berliterasi, komitmen dan semangat guru mengajar, program literasi dilaksanakan secara terjadwal, tersedianya sarana prasarana sekolah yang mendukung pelaksanaan literasi; Sedangkan faktor penghambatnya adalah guru masih belum menerima pembinaan dalam bentuk pelatihan untuk melaksanakan GLS, kondisi koleksi buku bacaan yang rusak, serta fungsi evaluasi GLS yang belum dilaksanakan secara menyeluruh.
\end{abstract}

Kata Kunci: Implementasi, Gerakan Literasi Sekolah, SDN 5 Menteng.

Abstract: Qualitative research with a case study design aims to describe the implementation of GLS in SDN 5 Menteng Palangka Raya, viewed from aspects: (1) stages of GLS implementation, (2) mechanism of GLS implementation, and (3) supporting factors and constraints in GLS implementation. The data sources in this study are the principal, librarian, and 2 class teachers. Data collection techniques carried out by observation, interviews, and documentation. Data analysis uses interactive data patterns from Miles and Huberman (1994). The results showed that: (1) The stages of GLS were carried out only in the initial stages (habituation of iteration) through reading and writing activities, (2) The mechanism of GLS implementation was carried out based on basic management principles, namely: GLS planning, GLS organizing, GLS mobilization, and GLS monitoring and evaluation, (3) Supporting factors for the implementation of GLS include the high interest of students to titrate, commitment and enthusiasm of teaching teachers, literacy programs carried out on a scheduled basis, the availability of school infrastructure that supports literacy; While the inhibiting factor is the teacher still has not received coaching in the form of training to implement GLS, the condition of the collection of damaged reading books, as well as the evaluation function of GLS that has not been implemented thoroughly.

Keywords: Implementation, School Literacy Movements, SDN 5 Menteng.

PENDAHULUAN

Pendidikan merupakan aspek mendasar yang menjadi tolak ukur kemajuan suatu bangsa. Pendidikan memiliki peranan yang sangat penting dalam pembangunan bangsa Indonesia yang terencana untuk mengembangkan kemampuan dalam membentuk watak pribadi seseorang dan segenap potensi yang ada pada diri manusia, agar menjadi 
manusia yang utuh secara jasmani dan rohani, serta mampu mengembangkan kemampuan yang ada dalam diri seorang manusia. Indonesia sendiri juga sangat memperhatikan tentang pendidikan. Citacita pendidikan bangsa Indonesia tersebut tertuang dalam Undang-Undang Dasar 1945, yaitu "untuk mencerdaskan kehidupan bangsa". Berdasarkan hasil survey yang dilakukan oleh PISA (Programme for International Student Assessment) 2009 menunjukkan peserta didik Indonesia berada pada peringkat ke57 dengan skor 396 (skor rata-rata OECD 493), sedangkan PISA 2012 menunjukkan peserta didik Indonesia berada pada peringkat ke-64 dengan skor 396 (skor rata-rata OECD 496). Sebanyak 65 negara berpartisipasi dalam PISA 2009 dan 2012. Peserta didik kesulitan untuk menguasai materi bacaan dan sulit untuk menjawab soal uraian yang memerlukan analisis logika, hal ini merupakan gambaran tentang bagaimana rendahnya kualitas literasi peserta didik Indonesia pada jenjang pendidikan dasar. Kurangnya minat membaca siswa merupakan penyebab utama rendahnya kualitas literasi peserta didik di Indonesia, siswa masih sangat bergantung pada guru sebagai sumber ilmu pengetahuan, sehingga minat untuk melakukan kegiatan membaca sangat rendah. Dari kedua hasil survey PISA tersebut, dapat dikatakan bahwa praktik pendidikan yang dilaksanakan di sekolah belum memperlihatkan fungsi sekolah sebagai organisasi pembelajaran yang berupaya menjadikan peserta didik terampil membaca untuk mendukung mereka sebagai pembelajar sepanjang hayat (Kemendikbud, 2016:1). Berdasarkan fakta tersebut, maka pemerintah melalui Permendikbud Nomor 23 tahun 2015 tentang budi pekerti menggalakkan program literasi yang dinamakan Gerakan Literasi Sekolah (GLS). Pengertian literasi dalam konteks GLS adalah kemampuan mengakses, memahami, dan menggunakan sesuatu secara cerdas melalui berbagai aktivitas, antara lain membaca, melihat, menyimak, menulis dan/berbicara. Melalui adanya program GLS ini pemerintah berusaha meningkatkan minat baca peserta didik yang menjurus pada pengembangan budi pekerti dan kemampuan peserta didik untuk dapat memahami materi bacaan secara utuh dalam rangka mempersiapkan diri mereka sebagai pembelajar sepanjang hayat.

Program GLS sejatinya memiliki tiga tahapan yang disesuaikan dengan kesiapan sekolah, yaitu tahap pembiasaan, tahap pengembangan, dan tahap pembelajaran (Kemendikbud, 2016:5). Surabaya menjadi contoh keberhasilan dalam melaksanakan program literasi. Adanya dukungan kebijakan dari pemerintah kota Surabaya dengan membuat program tantangan membaca yang mewajibkan kegiatan membaca bagi seluruh siswa setiap hari, fenomena yang nampak pada setiap sekolah di Surabaya dimana siswa diwajibkan membaca 2 buku dalam satu bulan dengan target capaian sekolah membaca 3000 buku setiap tahunnya. Dengan diwajibkannya kegiatan membaca ini memacu para siswa di kota Surabaya untuk lebih mengasah kemampuan dalam berliterasi, yang mana siswanya tidak hanya terampil membaca namun telah bisa membuat karya tulisan sendiri. Melalui program literasi para siswa di kota Surabaya telah mampu mengakses dan memahami informasi melalui membaca serta menyampaikan kembali informasi tersebut melalui karya tulisan mereka sendiri. Kota Palangka Raya juga telah melaksanakan program GLS, salah satu sekolah yang telah melaksanakan program GLS yang telah berjalan dengan baik yaitu pada jenjang pendidikan dasar di SDN 5 Menteng. Kegiatan literasi di SDN 5 Menteng telah diprogramkan dalam salah satu misi sekolah yang menunjukan keseriusan SDN 5 Menteng dalam mewujudkan tujuan GLS di sekolah untuk menumbuhkembangkan budaya membaca 
yaitu melalui kegiatan 15 menit membaca bagi semua peserta didik. Pentingnya kegiatan membaca dalam GLS tentu memberi hal positif bagi peserta didik, beberapa manfaat dari kegiatan membaca, yaitu: (1) meningkat kadar intelektul; (2) memperoleh berbagai pengetahuan hidup; (3) memiliki cara pandang dan pola pikir yang luas; (4) memperkaya perbendaharaan kata; (5) mengetahui berbagai peristiwa yang terjadi di berbagai belahan dunia; (6) meningkatkan keimanan; (7) mendapatkan hiburan (Rachmawati, 2008:4). Pada SDN 5 Menteng Palangka Raya, kepala sekolah bertanggung jawab langsung dalam proses berjalannya GLS secara menyeluruh di lingkungan sekolah dengan memberikan arahan, saran, dan bimbingan kepada guru kelas maupun tenaga pustakawan dalam melaksanakan kegiatan literasi untuk mengarahkan, membimbing, dan memotivasi siswa agar menjadi tertarik dalam kegiatan berliterasi, khususnya membaca dan menulis. Kegiatan GLS, 15 menit membaca, di SDN 5 Menteng disebut dengan kegiatan literasi kelas yang juga selain itu didukung dengan program kegiatan kunjung perpustakaan. Sehingga, berjalannya GLS di SDN 5 Menteng dilakukan melalui dua macam kegiatan, yaitu kegiatan literasi kelas dan kegiatan kunjung perpustakaan.

Kegiatan literasi kelas dilakukan selama 15 menit setiap hari, dimana siswa diarahkan oleh guru kelas untuk melakukan aktivitas baik di dalam maupun di luar kelas seperti membaca, mengamati, atau menulis. Pada akhir kegiatan siswa diarahkan kembali oleh guru kelas untuk menyampaikan tanggapannya terhadap aktivitas yang dilakukannya dapat secara langsung maupun tertulis dalam bentuk rangkuman. Sedangkan kegiatan kunjung perpustakaan dilakukan seminggu sekali secara terjadwal untuk satu kelas per minggunya dengan durasi 30 menit untuk membaca maupun menyimak buku bergambar, baik buku cerita maupun buku pelajaran yang tersedia diperpustakaan. Pada kegiatan ini peran guru dibantu oleh tenaga pustakawan dalam memberikan arahan dan bimbingan kegiatan membaca. Seperti kegiatan literasi kelas, selesai kegiatan kunjung perpustakaan siswa diarahkan untuk mengekspresikan pendapatnya terhadap buku bacaan yang telah disimaknya baik secara lisan maupun tertulis. Kedua kegiatan tersebut telah terlaksana dalam menunjang program GLS untuk menumbuhkan minat baca siswa di SDN 5 Menteng Palangka Raya. Selain itu, lingkungan sekolah yang kaya literasi juga telah tercipta di SDN 5 Menteng, yang nampak dari banyaknya media baca seperti mading, poster, atau kliping, atau gambar kartun yang merupakan hasil karya siswa terpampang di berbagai sudut dinding ruang kelas maupun luar kelas, karya literasi yang penuh warna dan menarik sehingga memotivasi siswa yang lain untuk membaca/melihat isi bacaan yang disampaikan.

\section{METODE}

Penelitian ini menggunakan pendekatan kualitatif dengan rancangan studi kasus. Studi kasus yang pada hakekatnya meneliti kasus, dimana kasus tersebut diperlukan dan penting untuk menguji suatu teori yang telah tersusun dengan baik. Studi kasus juga dimaknai kasus organisasi, yaitu studi kasus untuk mendapatkan informasi tentang keterangan-keterangan organisasi dimana peneliti ingin mengetahui bagaimana kehidupan orang-orang dalam organisasi tersebut. Penelitian dilakukan di SDN 5 Menteng Kota Palangka Raya. Penentuan informan dilakukan dengan teknik pengambilan sampel secara purposive sampling dan snowball sampling dengan maksud agar diperoleh data dan informasi dari orang-orang yang benar-benar mengetahui secara mendalam terkait fokus penelitian sehingga data yang diterima dapat lebih akurat. Dari informan pertama, maka akan berkembang ke 
informan kedua dan seterusnya sehingga diibaratkan seperti bola salju. Hal itu sejalan dengan yang dikatakan oleh Ulfatin (2014:181), begitu informan kunci pertama diwawancarai secukupnya, ia diminta untuk menunjukkan satu atau lebih sumber lain yang dianggapnya memiliki informasi yang dianggap relevan dan memadai, sehingga dapat dijadikan sebagai informan berikutnya. Dari informan kedua yang ditunjuk oleh informan pertama, kemudian ia diminta untuk menyebutkan sumber lain yang dapat dijadikan informan berikutnya lagi.

Dengan cara inilah, informasi yang diperoleh peneliti menjadi semakin besar dengan melibatkan beberapa orang yang menurut Bogdan dan Biklen (1992) diibaratkan seperti bola salju (snowball sampling). Teknik pengumpulan data yang digunakan adalah (a) observasi, (b) wawancara mendalam, dan (c) studi dokumentasi. Informasi yang terkumpul dari ketiga teknik tersebut dianalisis secara berulang dengan menggunakan alur pola interaktif. Analisis data penelitian Miles dan Huberman yang meliputi reduksi data, penyajian data, dan penarikan kesimpulan. Pengecekan kredibilitas data dilakukan dengan teknik triangulasi (sumber dan teknik/metode), member checks, dan kecukupan bahan referensi; pengecekan dependabilitas data penelitian dilakukan oleh peneliti mulai dari melakukan penelitian, penyusunan transkrip wawancara sampai dengan penulisan laporan hasil penelitian dan pelaksanaan penelitian sesuai dengan jadwal yang telah disepakati bersama; dan pengecekan konfirmabilitas digunakan untuk melihat bahwa hasil penelitian yang dilakukan menunjukkan adanya proses penelitian di lapangan.

\section{HASIL DAN PEMBAHASAN}

\section{Tahapan Implementasi GLS}

Berdasarkan hasil penelitian diketahui bahwa implementasi GLS di SDN 5 Palangka Raya baru dilaksanakan pada tahap awal yaitu tahap pembiasaan, hal ini mengingat bahwa program GLS di SDN 5 Menteng Palangka Raya belum lama berjalan, juga karena ditunjang oleh kemampuan sekolah dalam menyediakan sarana dan prasarana literasi yang hanya mencukupi untuk melakukan literasi pada tahapan pembiasaan. Tujuan GLS di SDN 5 Menteng Palanga Raya pada tahapan pembiasaan adalah untuk menumbuhkembangkan budaya berliterasi melalui berbagai aktivitas seperti membaca, menulis, bernyanyi, bercerita, menyimak, dan melihat, yang dilakukan selama 15 menit sebelum belajar setiap hari sekolah. Pada tahapan pembiasaan ini tidak ada tagihan wajib yang berpengaruh pada nilai akademik oleh guru kepada siswa yang telah melakukan kegiatan literasi.

Hasil penelitian tentang implementasi GLS di SDN 5 Menteng Palangka Raya yang baru dilaksanakan pada tahap awal yaitu tahap pembiasaan melalui berbagai aktivitas seperti membaca, menulis, bernyanyi, bercerita, menyimak, dan melihat, yang dilakukan selama 15 menit sebelum belajar setiap hari sekolah di atas sejalan dengan Kemendikbud (2016) bahwa program literasi dapat diawali dengan melalukan kegiatan pembiasaan yang antara lain bertujuan untuk menumbuhkan minat peserta didik terhadap bacaan dan terhadap kegiatan membaca.

\section{Mekanisme Implementasi GLS}

Berdasarkan hasil penelitian diketahui bahwa implementasi GLS yang dilaksanakan di SDN 5 Menteng Palangka Raya dilaksanakan dengan mendasarkan pada prinsip dasar manajemen, yaitu perencanaan, pengorganisasi, penggerakan dan motoring dan evaluasi. Perencanaan GLS dilaksanakan dengan menetapkan tujuan GLS untuk menumbuhkembangkan budaya literasi yang dilakukan melalui rapat kerja yang diikuti oleh seluruh elemen sekolah baik guru, kepala sekolah dan seluruh karyawan. Rapat kerja ini dilakukan 
diawal semester. Rapat kerja berfungsi untuk menentukan program-program yang akan dilakukan dan mensosialisasikan apa saja peran dari masing-masing warga sekolah. Pengorganisasian GLS dilaksanakan dengan mengacu pada struktur organisasi sekolah yang sudah ada dalam menjalankan GLS. Pengorganasiaan dalam program GLS terstruktur dalam lingkup sekolah dari tingkat yang tertinggi yaitu kepala sekolah sebagai pengarah dan penanggungjawab program GLS secara menyeluruh, guruguru kelas yang telah menerima arahan dari kepala sekolah untuk melakukan kegiatan literasi di ruang kelas, tenaga pustakawan, serta warga sekolah lainnya yang mendukung berjalannya literasi. Penggerakan GLS dilaksanakan dengan menciptakan hubungan individual yang baik yang melibatkan unsur pimpinan dan bawahan yaitu arahan kerja dari kepala sekolah dengan gaya kepemimpinan terbuka atas segala masukan dan saran yang disambut positif sehingga memotivasi guru dalam melakukan literasi agar tujuan GLS dapat tercapai. Sedangkan pengawasan dilakukan dengan menentukan standar ketercapaian program GLS untuk menegukur sejauhmana keterlaksanaan dari program GLS dan bilamana perlu dilakukan upaya perbaikan agar implementasi GLS sesuai dengan yang direncanakan. Pengawasan terhadap implementasi GLS dilakukan oleh guru kelas melalui pengamatan langsung terhadap perubahan sikap dan perkembangan kemampuan literasi siswa, termasuk pula oleh kepala sekolah guna melihat kesesuaiaan hasil yang sudah dicapai dalam kegiatan literasi.

$$
\text { Hasil penelitian tentang }
$$

mekanisme implementasi GLS di atas sejalan dengan pendapat Hendrawati (2018) bahwa dalam melaksanakan program sekolah hendaknya dilaksanakan dengan menerapkan fungsi-fungsi prinsip dasar manajamen, yaitu perencanaan, pengorganisasian, penggerakan dan pengawasan sebagai upaya untuk mencapai tujuan sekolah.

\section{Faktor Pendukung dan Kendala}

Faktor pendukung dan kendala dalam implementasi GLS di SDN 5 Menteng Palangka Raya adalah: (1) Faktor pendukung: (a) adanya upaya untuk mensosialisasikan dan mengembangkan program GLS dari sekolah. Upaya tersebut diantaranya melalui rapat kerja guru maupun pertemuan dengan orang tua siswa, (b) adanya alokasi waktu dari sekolah untuk melakukan literasi secara terjadwal, (c) semangat dan komitmen mengajar yang baik dari guru-guru dalam mengarahkan siswa untuk berliterasi, (d) tingginya minat siswa untuk berliterasi, (e) tersedianya koleksi buku bacaan, dan (f) lingkungan sekolah yang kaya akan literasi, seperti banyaknya poster bergambar, tulisan-tulisan indah, serta suasana yang rindang. Sedangkan kendala yang dihadapi dalam implementasi GLS di sekolah, meliputi: (a) guru masih belum memperoleh pendidikan dan pelatihan secara komprehensif tentang Gerakan Literasi Sekolah, sehingga masih bergantung pada arahan dari kepala sekolah, (b) buku bacaan bergambar yang kaya akan nilai-nilai masih sedikit jumlah koleksinya, sehingga siswa menjadi mudah bosan terhadap sumber bacaan, (c) kondisi buku bacaan yang kurang baik seperti robek dan dicoret siswa, (d) teknis pelaksanaan GLS masih monoton, dan (e) belum adanya evaluasi secara menyeluruh.

\section{SIMPULAN}

Berdasarkan hasil penelitian dan pembahasan yang telah diuraikan sebelumnya, dapat dirumuskan kesimpulan sebagai berikut:

1. Implementasi GLS di SDN 5 Menteng Palangka Raya baru dilaksanakan pada tahap awal yaitu tahap pembiasaan, hal ini mengingat bahwa program GLS di SDN 5 Menteng Palangka Raya belum 
lama berjalan, juga karena ditunjang oleh kemampuan sekolah dalam menyediakan sarana dan prasarana literasi yang hanya mencukupi untuk melakukan literasi pada tahapan pembiasaan. Tujuan GLS di SDN 5 Menteng Palanga Raya pada tahapan pembiasaan adalah untuk menumbuhkembangkan budaya berliterasi melalui berbagai aktivitas seperti membaca, menulis, bernyanyi, bercerita, menyimak, dan melihat, yang dilakukan selama 15 menit sebelum belajar setiap hari sekolah. Pada tahapan pembiasaan ini tidak ada tagihan wajib yang berpengaruh pada nilai akademik oleh guru kepada siswa yang telah melakukan kegiatan literasi.

2. Mekanisme Implementasi GLS di SDN 5 Menteng Palangka Raya, dilaksanakan dengan mendasarkan pada prinsip dasar manajemen, yaitu perencanaan, pengroganisasian, penggerakan dan pengawasan.

3. Faktor pendukung dan kendala dalam implementasi GLS di SDN 5 Menteng Palangka Raya adalah: (a) Faktor pendukung: (1) adanya upaya untuk mensosialisasikan dan mengembangkan program GLS dari sekolah. Upaya tersebut diantaranya melalui rapat kerja guru maupun pertemuan dengan orang tua siswa, (2) adanya alokasi waktu dari sekolah untuk melakukan literasi secara terjadwal, (3) semangat dan komitmen mengajar yang baik dari guru-guru dalam mengarahkan siswa untuk berliterasi, (4) tingginya minat siswa untuk berliterasi, (5) tersedianya koleksi buku bacaan, dan (6) lingkungan sekolah yang kaya akan literasi, seperti banyaknya poster bergambar, tulisan-tulisan indah, serta suasana yang rindang. Sedangkan kendala yang dihadapi dalam implementasi GLS di sekolah, meliputi: (1) guru masih belum memperoleh pendidikan dan pelatihan secara komprehensif tentang Gerakan
Literasi Sekolah, sehingga masih bergantung pada arahan dari kepala sekolah, (2) buku bacaan bergambar yang kaya akan nilai-nilai masih sedikit jumlah koleksinya, sehingga siswa menjadi mudah bosan terhadap sumber bacaan, (3) kondisi buku bacaan yang kurang baik seperti robek dan dicoret siswa, (4) teknis pelaksanaan GLS masih monoton, dan (5) belum adanya evaluasi secara menyeluruh.

\section{UCAPAN TERIMA KASIH}

Terima kasih yang sebesarbesarnya diucapkan kepada pihak SDN 5 Menteng yang telah memberikan ijin serta berbagai fasilitas sehingga penulis dapat menyelesaikan penelitian ini, serta pihak Redaksi Equity in Education Journal (EEJ) yang telah memberikan kesempatan artikel saya dapat dimuat dalam jurnal ini.

\section{DAFTAR PUSTAKA}

Bogdan, R. C., \& Biklen, S. K. (1992). Qualitative Research for Education, second edition. USA: Allyn and Bacon.

Hendrawati, S. (2018). Fungsi-Fungsi Manaemen Sekolah. Diakses 19 Maret 2018, dari: https://www.academia.edu/11289 318/Fungsi_Manajemen_Sekolah.

Kemendikbud. (2016). Desain Induk Gerakan Literasi Sekolah. Jakarta: Direktorat Jenderal Pendidikan Dasar dan Menengah Kementerian Pendidikan dan Kebudayaan Republik Indonesia.

Peraturan Menteri Pendidikan dan Kebudayaan Nomor 23 Tahun 2015 tentang Penumbuhan Budi Pekerti.

Rachmawati, F. (2008). Dunia di Balik Kata (Pintar Membaca). Yogyakarta: Citra Aji Parama.

Ulfatin, N. (2014). Metode Penelitian Kualitatif di Bidang Pendidikan: Teori dan Aplikasinya. Malang: Bayumedia Publishing.

Undang-Undang Dasar Tahun 1945. 